\title{
DESENVOLVIMENTO in vitro DE BROTAÇÕES DE CAFEEIRO EM DIFERENTES MEIOS DE CULTURA E REGULADORES DE CRESCIMENTO DE PLANTA
}

\section{DEVELOPMENT in vitro OF COFEE PLANTS IN DIFFERENT CULTURE MEDIUM AND PLANT GROWTH REGULATORS}

\author{
Adriana Madeira Santos JESUS ${ }^{1}$ \\ Samuel Pereira de CARVALHO ${ }^{2}$ \\ Fabíola VILLA ${ }^{3}$ \\ Moacir PASQUAL ${ }^{4}$ \\ Michelly CARVALHO ${ }^{5}$
}

\section{RESUMO}

A não existência de uma metodologia adaptada para a multiplicação clonal de C. arabica L. em escala comercial tem sido uma grande restrição a utilização dessa técnica como estratégia para viabilizar o uso de cafeeiros híbridos obtidos pelo melhoramento genético. Com o objetivo de aprimorar as técnicas de micropropagação de brotações de cafeeiro, foram instalados dois experimentos utilizando segmentos nodais de plântulas pré-estabelecidas in vitro de C. arabica. No primeiro experimento estudou-se o efeito de concentrações de $\operatorname{BAP}\left(6,9,12\right.$ e $\left.15 \mathrm{mg} \mathrm{dm}^{-3}\right)$ e ANA $\left(0,5 \mathrm{e} 1 \mathrm{mg} \mathrm{dm}^{-3}\right)$ sobre duas cultivares ('Catuaí Vermelho' e 'Maragogipe'), no meio MS. No segundo experimento avaliou-se a influência de concentrações de $\operatorname{BAP}\left(0,6,9,12\right.$ e $\left.15 \mathrm{mg} \mathrm{dm}^{-3}\right)$ e dois meios de cultura (MS e WPM) sobre três cultivares ('Catuaí Vermelho', 'Icatu' e 'Rubi'). Após 90 dias, melhores resultados para as cvs. Catuaí Vermelho e Maragogipe foram obtidos com $15 \mathrm{mg} \mathrm{dm}^{-3} \mathrm{de}$ BAP. A cultivar Catuaí Vermelho apresentou maior número de brotações quando comparada com a cv. Maragogipe. Na ausência de BAP, o meio WPM é mais indicado para se obter maior número de brotações da cv. Rubi. Melhores resultados para massa da matéria fresca das brotações verificaram-se em meio MS, para as cvs. Catuaí Vermelho e Icatu.

Palavras-chave: Coffea arabica L.; citocinina; auxina; MS; WPM.

\section{ABSTRACT}

The nonexistence of a methodology adapted for the asexual multiplication of $C$. arabica in commercial scale has been the largest restriction to the employment of this technique as strategy for the use of coffee hybrid obtained by the genetic improvement. With the objective of refine the micropropagation techniques of coffee shoots, nodal segments of plants preset in vitro of $C$. arabica was inoculated in culture medium. In a first experiment it was studied the effect on concentrations of BAP (benzilaminopurin) and concentrations of ANA (naftalenacetic acid) on 2 cvs. In the second experiment the influence of concentrations of BAP and 2 culture medium on $3 \mathrm{cvs}$. were also verified. The $\mathrm{pH}$ was adjusted for 5.8 before the addition of 7 $\mathrm{g} \mathrm{dm}^{-3}$ of agar and the sterilization to $121^{\circ} \mathrm{C}$ and $0,1 \mathrm{MPa}$ for $20 \mathrm{~min}$. After the inoculation, the explants was maintained in growth room at $26 \pm 1^{\circ} \mathrm{C}$, irradiance of $32 \mathrm{~mol} \mathrm{~m}^{-2} \mathrm{~s}^{-1}$ and photoperiod of 16 daily hours. The experiments were a design randomized complete blocks, being used four explants by repetition and 20 plants per treatment. After 90 days, better results for cvs. Catuaí Vermelho and Maragogipe were obtained with $15 \mathrm{mg} \mathrm{dm}^{-3}$ of BAP. The cv. Catuai Vermelho was presented larger shoots number when compared with cv. Maragogipe. In the absence of BAP, culture medium WPM is more indicated to obtain larger number of shoots of cv. Rubi. Better results in the fresh weight of shoots were verified in culture medium MS, for cvs. Catuai Vermelho and Icatu.

Key-words: Coffea arabica L.; cytokinin; auxin; MS; WPM.

\footnotetext{
${ }^{1}$ D.Sc., Pesquisadora da EPAMIG, Uberaba, MG, Brasil. E-mail: adriana.madeira@epamig.br

${ }^{2}$ D.Sc., Prof. Adjunto do Departamento de Agricultura (DAG), Universidade Federal de Lavras (UFLA), Caixa Postal 37, CEP. 37200-000, Lavras, MG, Brasil. E-mail: samuelpc@ufla.br

${ }^{3}$ D.Sc., Prof. ${ }^{a}$. Adjunta do Centro de Ciências Agrárias (CCA), Universidade Estadual do Oeste do Paraná (UNIOESTE), CEP. 85960-000, Marechal Cândido Rondon, PR, Brasil. E-mail: fvilla2003@libero.it

${ }^{4}$ D.Sc., Prof. Adjunto do Departamento de Agricultura (DAG), UFLA, Cx. Postal 37, CEP. 37200-000, Lavras, MG, Brasil. E-mail: mpasqual@ufla.br

${ }^{5}$ Doutoranda em Fitotecnia, Universidade Federal de Viçosa (UFV), Viçosa, MG, Brasil. E-mail: mcarv78@yahoo.com.br
} 
JESUS, A. M. S. et al. Desenvolvimento in vitro de brotações...

\section{INTRODUÇÃO}

O café é uma importante cultura no mundo econômico, principalmente para os países em desenvolvimento onde é produzido e para aqueles industrializados que são os principais consumidores. Também tem um grande significado social por causa da grande quantidade de trabalhadores envolvidos no cultivo. A principal espécie cultivada no País é o Coffea arabica, o qual responde por $90 \%$ da área total plantada (Ramos \& Almeida, 2005).

A propagação clonal de indivíduos geneticamente superiores, que expressam vigor híbrido, permitirá atender a crescente demanda dos produtores de café por cultivares mais produtivas e homogêneas. A micropropagação possibilita multiplicar em larga escala os genótipos selecionados, disponibilizando-os de forma mais rápida aos agricultores.

O sucesso na micropropagação está diretamente relacionado com os tipos de meio de cultura empregados e os componentes utilizados nesse meio, sendo que o uso de reguladores de crescimento de planta é considerado fator preponderante (Caldas et al., 1998). Combinações entre essas substâncias propiciam promoção de crescimento e desenvolvimento do explante (Rezende et al., 2008; Andrade et al., 2001). Um meio mínimo, sem adição de reguladores, raramente serve de veículo para suportar o crescimento de tecidos vegetais (Krikorian, 1991).

O meio de cultura MS (Murashige \& Skoog, 1962) é conhecido por apresentar elevado conteúdo de sais, enquanto o meio WPM (Loyd \& McCown, 1980) possui aproximadamente $1 / 4$ da concentração de íons nitrato de amônio na sua composição (Pasqual, 2001). Ribeiro et al. (2003), estudando diferentes meios de cultura no desenvolvimento in vitro de embriões zigóticos de $C$. arabica cvs. Topázio e Acaiá, observaram melhor desenvolvimento de plântulas em meio MS, sendo as respostas das cultivares mais satisfatórias para comprimento da parte aérea, massa da matéria fresca do sistema radicular, da parte aérea e massa da matéria seca total.

A cultura de segmentos nodais é uma das aplicações mais práticas da cultura de tecidos, abrange a maioria dos sistemas de Micropropagação, envolvendo o isolamento de órgãos meristemáticos pré-formados (normalmente gemas axilares) e a quebra da dominância apical (George, 1993). As gemas axilares que naturalmente se formam na inserções das folhas são estimuladas a crescer, dando origem a novas partes aéreas, que por sua vez repetem o mesmo processo. Obetem-se assim um grande número de plantas sadias e geneticamente uniformes, o que é uma vantagem ao uso da propagação via indireta onde ocorrem maiores taxas de variação somaclonal. As partes aéreas produzidas são em seguida enraizadas (Grattapaglia \& Machado ,1998).

Para quebrar a dominância apical e induzir a proliferação de gemas axilares, as citocininas são indispensáveis, sendo o tipo de citocinina e a sua concentração os fatores que mais influenciam o sucesso da micropropagação. Ramos \& Almeida (2005) concluíram que a multibrotação de explantes nodais de $C$. arabica cv. Mundo Novo pode ser induzida por 10 a $30 \mathrm{mg} \mathrm{dm}^{-3}$ de BAP. Embora não sejam essenciais para esta fase, as auxinas podem ser utilizadas para favorecer o crescimento da parte aérea de plântulas de cafeeiro. Neste caso, é muito importante estabelecer uma relação citocinina/auxina superior a 1 , ou seja, utilizando-se meios de cultura com mais citocinina do que auxina, para favorecer a multiplicação ao invés do enraizamento (Pasqual, 2001).

Diante do exposto, objetivou-se avaliar o melhor meio de cultura e concentração de BAP (benzilaminopurina) e ANA (ácido naftaleno acético) na micropropagação de segmentos nodais de cafeeiro cvs. Maragogipe, Catuaí Vermelho, Icatu e Rubi, visando aumentar a multiplicação das cultivares e o desenvolvimento das brotações.

\section{MATERIAL E MÉTODOS}

No primeiro experimento, segmentos nodais provenientes de plântulas de Coffea arabica L., cvs. Maragogipe e Catuaí Vermelho, préestabelecidas in vitro, foram inoculadas primeiramente em meio de cultivo MS acrescido de 4 concentrações de $\operatorname{BAP}\left(6,9,12\right.$ e $\left.15 \mathrm{mg} \mathrm{dm}^{-3}\right)$ e 2 de ANA $\left(0,5\right.$ e $\left.1 \mathrm{mg} \mathrm{dm}^{-3}\right)$, perfazendo um total de 16 tratamentos em fatorial $2 \times 4 \times 2$, com 5 repetições de 4 segmentos nodais por repetição.

O segundo experimento constou também de plântulas pré-estabelecidas in vitro de C. arabica L. cvs. Catuaí Vermelho, Icatu e Rubi, cujos segmentos nodais foram inoculadas nos meios MS (Murashige \& Skoog, 1962) e WPM (Loyd \& McCown, 1980), acrescidos de cinco concentrações de $\operatorname{BAP}\left(0,6,9,12\right.$ e $\left.15 \mathrm{mg} \mathrm{dm}^{-3}\right)$, perfazendo um total de 30 tratamentos em fatorial $2 \times 5 \times 3$, com 4 repetições de 5 segmentos nodais por repetição. Os meios de cultura foram ajustados para $\mathrm{pH} \mathrm{5,8}$ antes da adição de ágar a $7 \mathrm{~g} \mathrm{dm}^{-3}$ e posteriormente autoclavados a $121{ }^{\circ} \mathrm{C}$ e $0,1 \mathrm{MPa}$ de pressão durante $20 \mathrm{~min}$. Os explantes foram inoculados em tubos de ensaio $(20 \times 150 \mathrm{~mm})$, contendo $15 \mathrm{~cm}^{3}$ do meio de cultura e posteriormente transferidos para sala de crescimento a $26 \pm 1{ }^{\circ} \mathrm{C}$, irradiância de 32 $\mu \mathrm{mol} \mathrm{m} \mathrm{m}^{-2} \mathrm{~s}^{-1}$ e fotoperíodo de $16 \mathrm{~h}$, permanecendo nestas condições por 90 dias.

O delineamento experimental, nos dois casos, foi o inteiramente casualisado e as variáveis analisadas foram os comprimentos de brotações (cm), número de brotações e massa da matéria fresca e seca das brotações (g) das plântulas de cafeeiro. Os resultados foram submetidos à análise de variância, utilizando-se do software Sisvar (Ferreira, 2000) e aplicando regressão polinomial para concentrações de BAP e de ANA e teste de Tukey para os tipos de meio. 
JESUS, A. M. S. et al. Desenvolvimento in vitro de brotações...

\section{RESULTADOS E DISCUSSÃO}

Nos resultados do primeiro experimento com cultivares $x$ ANA x BAP, verificou-se interação significativa tripla e de ANA $\times$ BAP para o número das brotações e apenas de ANA x BAP para a massa da matéria seca da parte aérea das plântulas de cafeeiro. Não foi observada interação significativa entre cultivares $x$ ANA para nenhuma das variáveis estudadas.

Para comprimento de brotações apenas cultivares e BAP tiveram resultados significativos, sendo que maior comprimento $(0,585 \mathrm{~cm})$ foi observado na cv. Maragogipe (Tabela 1). Em contrapartida, maior massa de matéria seca de brotações foi obtido com a cultivar Catuaí Vermelho (Tabela 1). Esse resultado pode ser explicado pelo fato de que a cultivar Catuaí apresentou número de brotações significativamente maior do que a cultivar Maragogipe (Figura 1B). As respostas de desenvolvimento in vitro são regidas pela constituição genética da planta (Hu \& Ferreira, 1998). A capacidade para a neoformação de gemas em segmentos nodais de cafeeiro varia de uma espécie para outra (Krikorian, 1991).

TABELA 1 - Comprimento e massa da matéria seca de brotações em segmentos nodais de Coffea arabica L. cvs. Catuaí Vermelho e Maragogipe, inoculados em meio MS ${ }^{(1)}$. UFLA, Lavras, MG.

\begin{tabular}{lcc}
\hline Cultivar & $\begin{array}{c}\text { Comprimento das } \\
\text { brotações }(\mathrm{cm})\end{array}$ & Massa da matéria seca de brotações $(\mathrm{g})$ \\
\hline Catuaí Vermelho & $0,457 \mathrm{~b}^{*}$ & $1,441 \mathrm{a}$ \\
Maragogipe & $0,585 \mathrm{a}$ & $0,836 \mathrm{~b}$ \\
\hline
\end{tabular}

${ }^{*}$ Médias seguidas por letras iguais, na coluna, não diferem entre si, pelo teste de Tukey, ao nível de $5 \%$ de probabilidade. ${ }^{(1)}$ Murashige \& Skoog, 1962.

A

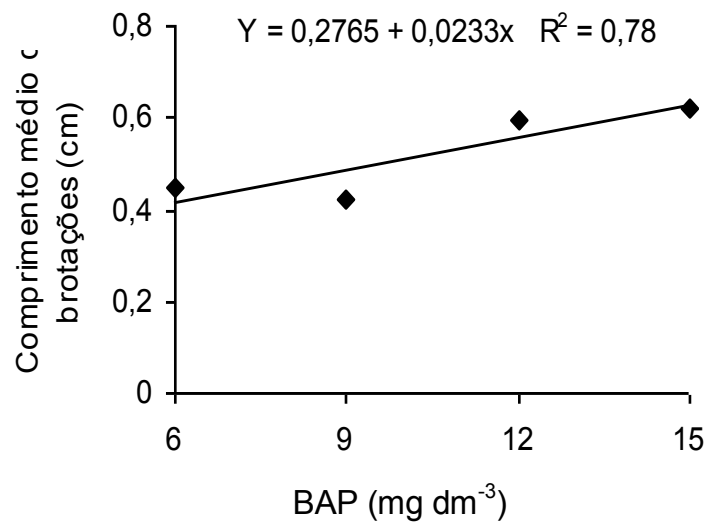

B

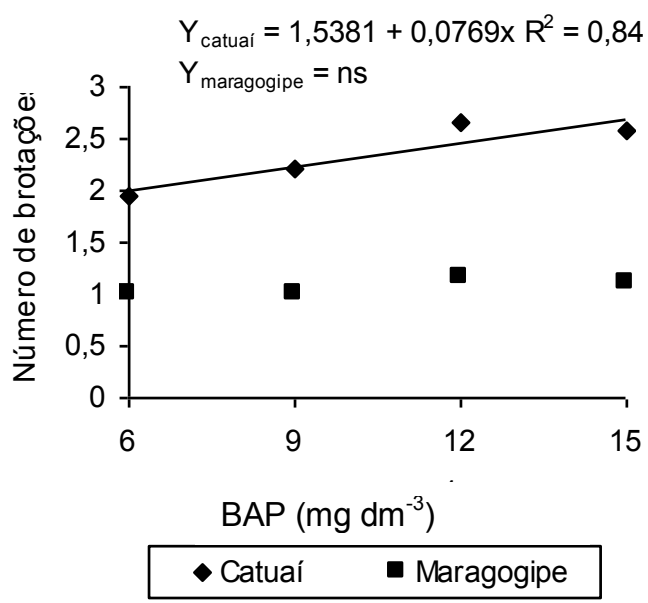

FIGURA 1 - Comprimento das brotações (A) e número de brotações (B) em segmentos nodais de Coffea arabica L. cvs. Catuaí Vermelho e Maragogipe, inoculados em meio MS adicionado de BAP (6benzilaminopurina). UFLA, Lavras, MG.

Efeito crescente das concentrações de BAP foi observado para comprimento e número de brotações (Figuras 1A e B). Com incrementos nas concentrações de BAP verificou-se aumento linear no número de brotos, corroborando CavalcanteAlves et al. (1999) que, ao estudar plântulas de cafeeiro cv. Catuaí Vermelho afirmou que as brotações eram obtidas com altas concentrações desse regulador associado a $20,0 \mathrm{mg} \mathrm{dm}^{-3}$ de $\mathrm{GA}_{3}$.

A ação da citocinina sobre os explantes demonstrou-se benéfica ao comprimento e proliferação de brotos, mesmo em concentrações mais elevadas. Lucas et al. (2006), porém, afirmam que concentrações elevadas de BAP promovem o desbalanceamento endógeno dos fitormônios, reduzindo $o$ crescimento das brotações $e$ aumentando a vitrificação. Resultados semelhantes a este trabalho foram observados por Pasqual \&
Barros (1991), cujo número de brotações foi influenciado por concentrações elevadas de BAP, acima de $5,0 \mathrm{mg} \mathrm{dm}^{-3}$. Jesus et al. (2002) também identificaram concentração elevada de $9,0 \mathrm{mg} \mathrm{dm}^{-3}$ de BAP para promoção da proliferação de brotos de C. arabica L.

Observou-se interação significativa entre BAP e ANA para massa da matéria seca das brotações de cafeeiro, com aumento linear em relação a incrementos nas concentrações de BAP (Figura 2). Maior massa da matéria seca das brotações foi verificado em tratamentos com altas concentrações da citocinina, corroborando com Carvalho et al. (1998) que, estudando a cv. Catuaí Vermelho verificaram melhores resultados para o massa da matéria seca em meio MS com a adição de $9,0 \mathrm{mg} \mathrm{dm}^{-3}$ de BAP e na ausência de $\mathrm{GA}_{3}$. 
JESUS, A. M. S. et al. Desenvolvimento in vitro de brotações...

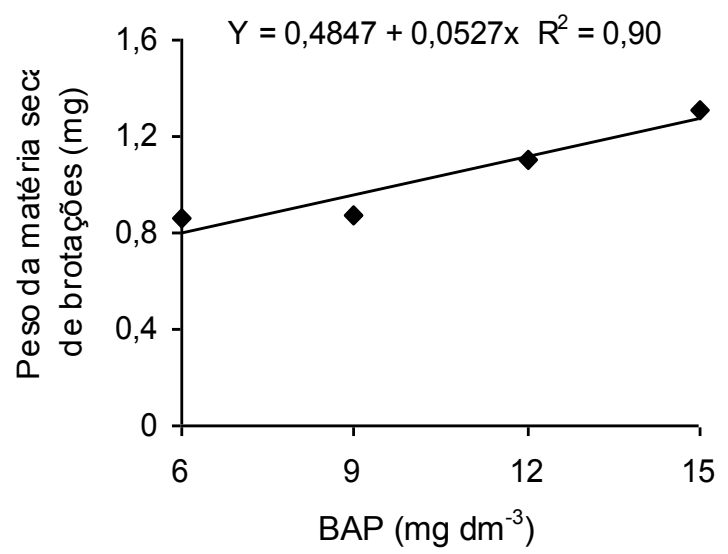

FIGURA 2 - Massa da matéria seca de brotações em segmentos nodais de Coffea arabica L. cvs. Catuaí Vermelho e Maragogipe, inoculados em meio MS adicionado de BAP (6-benzilaminopurina). UFLA, Lavras, MG.

As brotações atingiram maior massa de matéria seca no tratamento com $1,0 \mathrm{mg} \mathrm{dm}^{-3}$ de ANA, confirmando o efeito benéfico desta auxina no crescimento da parte aérea (Tabela 2). O efeito sinergético do ANA com o BAP verificado para as duas cultivares estudadas in vitro corroboram vários autores que citam que concentrações de ANA

abaixo de $2,0 \mathrm{mg} \mathrm{dm}^{-3}$ associadas ao BAP beneficiam a proliferação e alongamento de brotações de cafeeiro (Pasqual \& Barros, 1991). Carvalho et al. (1998) também verificaram resultado semelhante em brotações de $C$. arabica, cv. Catuaí Vermelho cultivada em meio MS com a adição de $9,0 \mathrm{mg} \mathrm{dm}^{-3}$ de BAP e na ausência de $\mathrm{GA}_{3}$.

TABELA 2 - Massa da matéria seca de brotações em segmentos nodais de Coffea arabica L. cvs. Catuaí Vermelho e Maragogipe, inoculados em meio MS com diferentes concentrações de ANA (ácido naftaleno acético). UFLA, Lavras, MG.

\begin{tabular}{cc}
$\begin{array}{c}\text { Regulador de crescimento } \\
\text { ANA }\left(\mathrm{mg} \mathrm{dm}^{-3}\right)\end{array}$ & $\begin{array}{c}\text { Massa da matéria seca de brotações } \\
(\mathrm{g})\end{array}$ \\
\hline 0,5 & $0,949 \mathrm{~b}^{*}$ \\
1,0 & $1,328 \mathrm{a}$
\end{tabular}

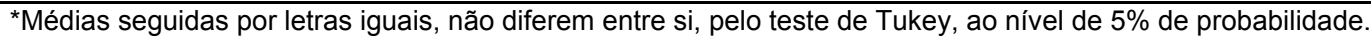

No segundo experimento com cultivares $x$ meios de cultura $x$ BAP, foram verificadas interações significativas de meios $x$ cultivares, meios $x$ BAP e cultivares $x$ BAP para número de brotações e massa da matéria fresca da parte aérea das plântulas. Para número das brotações, melhores resultados $(4,90)$ foram observados para a cultivar Catuaí Vermelho multiplicada em meio de cultura WPM (Tabela 3).

TABELA 3 - Número de brotações em segmentos nodais de Coffea arabica L. cvs. Catuaí Vermelho, inoculados em diferentes meios de cultura. UFLA, Lavras, MG.

\begin{tabular}{cc}
\hline Meios de cultura & Número de brotações \\
\hline WPM $^{(1)}$ & $4,90 \mathrm{a}^{*}$ \\
MS $^{(2)}$ & $3,71 \mathrm{~b}$
\end{tabular}

*Médias seguidas por letras iguais, não diferem entre si, pelo teste de Tukey, ao nível de $5 \%$ de probabilidade. ${ }^{(1)}$ Loyd \& McCown, 1980; ${ }^{(2)}$ Murashige \& Skoog, 1962.

As concentrações de $\mathrm{NO}^{-3}$ e $\mathrm{NH}^{+4}$ são bastante variáveis nos meios MS e WPM. O meio MS é mais concentrado em termos de macronutrientes, tendo uma concentração de 60 mmol destes dois componentes, em relação a 14,68 $\mathrm{mmol}$ no meio WPM, sendo quatro vezes mais concentrado que o WPM. Sendo assim, a forma e a concentração de nitrogênio podem ter tido influência significativa na síntese de citocininas endógenas, resultando em diferentes números de brotações por segmento nodal das espécies estudadas. Portanto, de acordo com os resultados obtidos neste estudo o meio MS é menos indicado na proliferação de brotos da cv. Catuaí Vermelho. 
JESUS, A. M. S. et al. Desenvolvimento in vitro de brotações...

$\mathrm{Na}$ Tabela 4 observa-se a interação significativa dos meios de cultura utilizados com as diferentes concentrações de BAP. Para as cultivares estudadas resultados de promoção de brotação foram observados em meio WPM tanto na ausência como na presença de $9,0 \mathrm{mg} \mathrm{dm}^{-3}$ de BAP. Para efeitos de uma futura redução de custos na produção de brotos de cafeeiro, o meio de cultivo indicado seria o WPM sem a adição da citocinina.

TABELA 4 - Número de brotações em segmentos nodais de Coffea arabica L., inoculados em meios de cultura com diferentes concentrações de BAP (6-benzilaminopurina). UFLA, Lavras, MG.

\begin{tabular}{ccc}
\hline BAP $\left(\mathrm{mg} \mathrm{dm}^{-3}\right)$ & Meios de cultura & Número de brotações \\
\hline 0 & WPM $^{(1)}$ & $5,60 \mathrm{a}^{*}$ \\
& MS $^{(2)}$ & $1,77 \mathrm{~b}$ \\
9 & WPM & $5,56 \mathrm{a}$ \\
& MS & $4,43 \mathrm{~b}$
\end{tabular}

${ }^{*}$ Médias seguidas por letras iguais, não diferem entre si, pelo teste de Tukey, ao nível de $5 \%$ de probabilidade. ${ }^{(1)}$ Loyd \& McCown, 1980; ${ }^{(2)}$ Murashige \& Skoog, 1962.

$\mathrm{Na}$ Tabela 5 verifica-se interação significativa entre as cultivares e o regulador de crescimento empregado. Na ausência de BAP a cultivar Rubi se destaca com 4,91 brotos por planta. Com concentrações maiores da citocinina (12 e 15 $\mathrm{mg} \mathrm{dm}^{-3}$ ) as cvs. Catuaí Vermelho e Rubi não diferem entre si estatisticamente, produzindo assim maior número de brotações enquanto a cultivar Icatu foi menos expressiva nestes tratamentos.

TABELA 5 - Número de brotações em segmentos nodais de Coffea arabica L., inoculados em meios de cultura com diferentes concentrações de BAP (6-benzilaminopurina). UFLA, Lavras, MG.

\begin{tabular}{ccc}
\hline BAP $\left(\mathrm{mg} \mathrm{dm}^{-3}\right)$ & Cultivares & Número de brotações \\
\hline \multirow{2}{*}{0} & Catuaí Vermelho & $3,81 \mathrm{~b}^{*}$ \\
& Rubi & $4,91 \mathrm{a}$ \\
& Icatu & $2,34 \mathrm{c}$ \\
\hline \multirow{2}{*}{12} & Catuaí Vermelho & $5,78 \mathrm{a}$ \\
& Rubi & $5,59 \mathrm{a}$ \\
& Icatu & $4,44 \mathrm{~b}$ \\
\hline \multirow{2}{*}{15} & Catuaí Vermelho & $5,84 \mathrm{a}$ \\
& Rubi & $5,53 \mathrm{a}$ \\
\end{tabular}

*Médias seguidas por letras iguais, não diferem entre si, pelo teste de Tukey, ao nível de $5 \%$ de probabilidade.

Para massa da matéria fresca da parte interação significativa para os meios de cultura e as aérea das brotações de cafeeiro foi verificada cultivares estudadas (Tabela 6).

TABELA 6 - Massa fresca da parte aérea de brotações em segmentos nodais de Coffea arabica L., inoculados em diferentes meios de cultura. UFLA, Lavras, MG.

\begin{tabular}{ccc}
\hline Meios de cultura & Cultivares & $\begin{array}{c}\text { Massa fresca da parte aérea } \\
\text { das brotações }\end{array}$ \\
\hline \multirow{2}{*}{ WPM $^{(1)}$} & Catuaí Vermelho & $0,33 \mathrm{~b}^{*}$ \\
& Rubi & $0,33 \mathrm{a}$ \\
& Icatu & $0,21 \mathrm{~b}$ \\
\hline \multirow{2}{*}{ MS $^{(2)}$} & Catuaí Vermelho & $0,36 \mathrm{a}$ \\
& Rubi & $0,29 \mathrm{~b}$ \\
& Icatu & $0,35 \mathrm{a}$ \\
\hline
\end{tabular}

*Médias seguidas por letras iguais, não diferem entre si, pelo teste de Tukey, ao nível de $5 \%$ de probabilidade. ${ }^{(1)}$ Loyd \& McCown, 1980; ${ }^{(2)}$ Murashige \& Skoog, 1962.

Scientia Agraria, Curitiba, v.11, n.6, p.431-436, Nov./Dec. 2010. 
JESUS, A. M. S. et al. Desenvolvimento in vitro de brotações...

Em meio WPM, a cv. Rubi se destacou por apresentar maior matéria fresca da parte aérea e no meio MS as cvs. Icatu e Catuaí Vermelho. A concentração de cada meio de cultivo utilizado é considerada ideal na obtenção de maior massa de matéria fresca de $C$. arabica, conforme descrito por Hu \& Ferreira (1998), que afirmam que respostas de desenvolvimento in vitro de qualquer espécie, são regidas pela constituição genética da própria planta. De forma semelhante, aos resultados obtidos no presente trabalho, diversos autores também observaram diferentes respostas de brotação em segmentos nodais de cultivares de $C$. arabica
(Lacerda et al., 2008; Santos, 2001).

\section{CONCLUSÕES}

$\mathrm{Na}$ ausência de BAP, o meio WPM foi mais indicado para se obter maior número de brotações da cv. Rubi.

Concentrações elevadas dessa citocinina promoveram o desenvolvimento de brotações das cvs. Catuaí Vermelho e Rubi.

Melhores resultados na massa da matéria fresca das brotações foram verificados em meio MS, para as cvs. Catuaí Vermelho e Icatu.

\section{REFERÊNCIAS}

1. ANDRADE, L.M.C.O.; PASQUAL, M.; MACIEL, A.L.R. et al. Cultura in vitro de embriões de Coffea arabica: influência de NAA e BAP. Ciência e Agrotecnologia, v. 5, n. 5, p. 1063-1070, 2001.

2. CALDAS, L.S., HARIDASAN, P.; FERREIRA, M.E. Meios nutritivos. In: TORRES, A.C.; CALDAS, L.S.; BUSO, J.A (eds.). Técnicas e aplicações da cultura de tecidos de plantas. Brasília: ABCTP/EMBRAPA, 1998. p. 87-132.

3. CARVALHO, G.R.; PASQUAL, M.; GUIMARÃES, R.J. et al. Efeito do ácido giberélico e benzilaminopurina no crescimento in vitro de embriões do cafeeiro cv. Acaia. Pesquisa Agropecuária Brasileira, v. 33, n. 6, p. 8-15, 1998.

4. CAVALCANTE-ALVES, J.M.; ANDRADE, L.M.C.O.; PASQUAL, M. et al. Micropropagação de Coffea arabica L.: influência de BAP e $\mathrm{GA}_{3}$. Revista Unimar, v. 8, n. 4, p. 95-100, 1999.

5. FERREIRA, D.F. Análises estatísticas por meio do Sisvar para Windows versão 4.0. In: REUNIÃO ANUAL DA REGIÃO BRASILEIRA DA SOCIEDADE INTERNACIONAL DE BIOMETRIA, 45., 2000, São Carlos. Anais... São Carlos: UFSCar, 2000. p. 255-258.

6. GEORGE, E.F. Plant propagation by tissue culture. Part 1. The technology. 2. ed. Edington: Exegetics, 1993. 574 p.

7. GRATTAPAGLIA, D.; MACHADO, M.A. Micropropagação. In: TORRES, A.C.; CALDAS, L.S.; BUSO, J.A. (Eds.). Cultura de tecidos e transformação genética de plantas. Brasília: EMBRAPA/ CNPH, 1998. p.183-260.

8. HU, C.Y.; FERREIRA, A.G. Cultura de embriões. In: TORRES, A.C.; CALDAS, L.S.; BUSO, J.A. (Eds.). Cultura de tecidos e transformação genética de plantas. Brasília: EMBRAPA-SPI/EMBRAPA-CNPH, 1998. p. 371-393.

9. JESUS, A.M.S.; CARVALHO, S.P.; PASQUAL, M. et al. Micropropagação do cafeeiro com concentrações de BAP em meio de pré-cultivo e de BAP e TDZ em meio de subcultivo. Revista Ceres, v. 69, n. 283, p. 253-263, 2002.

10. KRIKORIAN, A.D. Medios de cultivo: generalidades, composición y preparación. In: ROCA, W.M.; MROGINSKI, L.A. (Eds.). Cultivo de tejidos en la agricultura: fundamentos e aplicaciones. Cali: CIAT, 1991. p. 41-47.

11. LACERDA, G.A.; CHALFUN-JÚNIOR, A.; PAIVA, L.V. et al. Influência de reguladores de crescimento no desenvolvimento radicular de sementes de Coffea arabica L. 'Rubi' in vitro. Coffee Science, v. 3, n. 1, p. 81-84, 2008.

12. LOYD, G.; McCOWN, B. Commercially-feasible micropropagation of mountain laurel, Kalmia latifolia, by use of shoot-tip culture. International Plant Propagation Society Proceedings, v. 30, n. 3, p. 421-427, 1980.

13. LUCAS, M.A.K.; SAMPAIO, N.V.; PEREIRA, D.D. et al. Multiplicação in vitro do porta-enxerto de videira Paulsen 1103 com benzilaminopurina e ácido indolbutírico. Plant Cell Culture \& Micropropagation, v. 2, n. 1, p. 29-34, 2006.

14. MURASHIGE, T.; SKOOG, F.A. A revised medium for rapid growth and bioassays with tobacco tissue cultures. Physiologia Plantarum, v. 15, n. 3, p. 473-497, 1962.

15. PASQUAL, M. Cultura de tecidos vegetais: tecnologia e aplicações: meios de cultura. Lavras: UFLA/FAEPE, 2001. 74 p.

16. PASQUAL, M.; BARROS, I. Efeito de benzilaminopurina e ácido naftaleno acético na proliferação e elongação de brotações micropropagadas em Coffea arabica "in vitro". Pesquisa Agropecuária Brasileira, v.26, n.2, p.201-204, 1991.

17. RAMOS, L.C.; ALMEIDA, J.A.S. Efeito de 6-BA na brotação de gemas de explantes nodais de Coffea arabica cv. Mundo Novo. Bragantia, v. 64, n. 2, p. 185-190, 2005.

18. REZENDE, J.; PASQUAL, M.; CARVALHO, S.P. et al. Influência do meio de cultura e concentração de ágar no crescimento e desenvolvimento de plântulas de café oriundas da embriogênese somática direta. Scientia Agraria, v. 9, n.1, p. 21-26, 2008

19. RIBEIRO, L.S.; PASQUAL, M.; MACIEL, A.N.R. et al. Desenvolvimento in vitro de embriões zigóticos de Coffea arabica. Ciência e Agrotecnologia, v. 27, n. especial, p. 1479-1483, 2003.

20. SANTOS, C.G. Micropropagação e caracterização bioquímico anatômica em Coffea arabica e Coffea canephora. 2001. 110 f. Dissertação (Mestrado em Fisiologia Vegetal) - Universidade Federal de Lavras, Lavras, 2001.

21. ZARR, J.B.; MAPES, M. Action of growth regulators. In: BONGA, J.M.; DURZAN, D.J. Tissue culture in forestry. 2. ed Dordrecht: Martinus Nijhoff, 1985. p. 231-255.

Recebido em 28/10/2009

Aceito em 22/10/2010 